\title{
'VOCÊ QUASE GANHOU UM ORQUÍDEA VIVA!': DISSIMULAÇÃO QUEER E DESEJO HOMOSSOCIAL EM OS CAFAJESTES (1962) DE RUY GUERRA
}

\author{
'VOCÊ QUASE GANHOU UM ORQUÍDEA VIVA!': \\ QUEER DECEPTION AND HOMOSOCIAL DESIRE IN \\ RUY GUERRA'S OS CAFAJESTES (1962)
}

\section{JAMES HODGSON*}

RESUMO: Este artigo examinará temas queer em um dos primeiros exemplares do Cinema Novo, Os cafajestes, de Ruy Guerra. Por meio de uma análise do filme, este artigo defenderá a importância de uma leitura queer e observará a existência de temas queer tanto na trama como na mensagem política geral da obra. Dessa forma, este artigo explora como a teoria queer ocidental pode ser usada para se compreender o cinema político brasileiro da década de 1960. Ele conclui, em parte, que, por meio do complemento da perspectiva marxista com uma análise queer, pode-se demonstrar que Os cafajestes proporciona ao público um diagnóstico potente e multifacetado da opressão.

PALAVRAS-CHAVE: cinema, teoria queer, Ruy Guerra, Eve Sedgwick.

ABSTRACT: This article will examine queer themes in one of the earliest examples of Cinema Novo, Ruy Guerra's Os cafajestes. Through a close reading of the film, this article traces queer themes in both the plot and in the film's broader political message. As such, this article explores one way in Western queer theory might be used to understand Brazilian political cinema of the 1960s. It finds, in part, that when a queer critique complements a Marxist perspective, Os cafajestes can be shown to present viewers with a potent and multifaceted diagnosis of oppression.

KEYWORDS: cinema, queer theory, Ruy Guerra, Eve Sedgwick.

\footnotetext{
* Doutor pela University of Manchester, Grã-Bretanha. Agora trabalha como pesquisador Posdoutorado na University of Manchester.
} 


\section{ntrodução}

A sexualidade queer no cinema brasileiro tem atraído o interesse de uma gama de pesquisadores recentemente. Embora estudos iniciais geralmente lamentem a representação de gays e lésbicas na cinematografia nacional (MORENO, 1995; TREVISAN, 1986), vários novos trabalhos esforçam-se em elucidar a complexidade deste tópico (HODGSON, 2018; SUBERO, 2016; NETO, 2015; DE AZEVEDO; CUNHA, 2013; HODGSON, 2013).

O Cinema Novo, um importante conjunto de filmes na história cinematográfica do Brasil, e um dos mais estudados, atraiu até o momento poucos estudiosos da temática queer. Para corrigir esta lacuna, este artigo tem como objetivo identificar os temas queer em Os cafajestes, de Ruy Guerra.

Trata-se de um filme canônico?

O filme de Guerra é considerado um exemplar mais antigo, até mesmo prototípico do Cinema Novo (JOHNSON; STAM, 1995, p. 32-36). De qualquer maneira, Anderson Lopes Silva e Regina Ribeiro julgam ser Os cafajestes, Os fuzis e Deus e o diabo na terra do sol a principal "tríade do Cinema Novo" e enfatizam a importância do filme para o então nascente movimento cinematográfico (DA SILVA; RIBEIRO, 2014, p. 448). Jean-Claude Bernardet e Randal Johnson, que contribuíram com análises marxistas fundamentais do filme, também compartilham essa visão da sua influência (BERNARDET, 1977; JOHNSON, 1984).

A meu ver, Os cafajestes ainda carece de análise sob uma perspectiva queer. Em vez de explorar - como Azevedo e Cunha o fizeram - um filme de conteúdo claramente queer, como Madame Satã (DE AZEVEDO; CUNHA, 2013), pretendo realizar o tipo de leitura discutida por Alan Sinfield - uma leitura da obra "against the grain" (SINFIELD, 2005, p. 8-10). Mais especificamente, argumentarei que o foco na maneira como o desejo complica as relações masculinas pode enriquecer nossa compreensão das qualidades polêmicas do filme e expandir o entendimento de como a obra mina posições ideológicas hegemônicas. Para tanto, trabalharei com um dos mais antigos exemplos de teoria queer: Between men: english literature and male homosocial desire, de Eve Sedgwick (1985). Justifica-se o uso de uma abordagem antiga não só por ela facilitar a produção de uma leitura ainda pouco explorada, mas também porque o filme coloca as relações entre homens e mulheres como seu tema central - em especial, a possibilidade de exploração das normas de romance e amor para ganhos financei- 
ros. A teoria de Sedgwick, explicada abaixo, torna-se ideal para a exploração do tema, pois permite a descrição de tensões entre os homens que permanecem recônditas. Portanto, descreverei como o filme molda os laços masculinos dentro da ideologia opressiva e contra ela. Além disso, demonstrarei como os desejos homossexual reprimido e homossocial informam a obra de súbita, porém potente. Assim, este artigo contribui para uma abertura generalizada do cânone cinematográfico brasileiro a interpretações queer. Ele sugere uma maneira como a teoria de Sedgwick pode ser apropriada por estudiosos latino-americanos interessados em explorar artefatos culturais ostensivamente heterossexuais. Ao mesmo tempo, este estudo ilumina as armadilhas e limitações de tal enfoque.

\section{Cinema Novo e o Triângulo de Sedgwick}

O Cinema Novo emergiu no cenário brasileiro no início da década de 1960, em um meio cultural e político bastante influenciado pelo governo de Juscelino Kubitschek e a estabilidade socioeconômica do período. Em consequência do programa desenvolvimentista de Kubitschek, houve grande influxo de investimento estrangeiro no setor industrial do Brasil, acompanhado de uma retórica nacionalista cujo objetivo era promover a solidariedade social e a união nacional. Durante essa época, intelectuais e artistas brasileiros começaram a expressar preocupação com os efeitos da industrialização em larga escala sobre a classe operária e também com a crescente influência do capital estrangeiro nas searas política e econômica. O Cinema Novo pode ser visto como uma resposta direta a essas aflições. Com inspiração na crítica ideológica marxista, os diretores envolvidos no movimento tinham por objetivo desafiar o status quo, denunciar os efeitos negativos da política desenvolvimentista e tirar a população de seu estado de alienação. Muitos dos filmes dessa primeira fase do Cinema Novo, portanto, preocupam-se com mudança social, o que frequentemente tomava a forma de crítica da alienação sob o capitalismo, como se dá em Os cafajestes. Em verdade, conforme críticos em geral comentaram, Os cafajestes concentra-se em membros amorais e vazios da classe média que prosperaram durante o governo Kubitschek (JOHNSON, 1984, p. 97). Do ponto de vista cinematográfico, o Cinema Novo mistura uma gama de estilos e abordagens, da nouvelle vague ao neorrealismo italiano. 
Para fazer sua crítica social, os filmes do movimento frequentemente incluíam elementos como atores amadores, o método brechtiano e cenas de denúncia de situações de extrema pobreza. Geralmente, como o próprio Guerra explica, esses filmes eram produzidos com orçamento precário (CHAVES; CABAÇO, 2012, p. 138). Comparado com as transgressões formais de um Deus e o diabo na terra do sol ou Terra em transe, Os cafajestes assemelha-se mais a um drama convencional de Hollywood do que a uma obra cinematográfica radical. Mesmo assim, como mostrarei a seguir, o filme contém elementos estilísticos brechtianos que, a meu ver, permitem problematizar certas percepções sobre desejo e sexualidade. Para desenvolver essa análise, explicarei e aplicarei o conceito de Eve Sedgwick sobre as relações de desejo entre homens.

Sedgwick, uma das primeiras estudiosas a escrever sobre teoria queer no meio acadêmico norte-americano, cria um neologismo ao combinar "homossocial" com "desejo" e o usa para diagnosticar o que é, de fato, homossexualidade reprimida em diversos textos literários (SEDGWICK, 1985, p.1). A palavra "homossocial" pertence às ciências sociais e descreve laços sociais entre pessoas do mesmo sexo. "Desejo" deve ser entendido em termos psicanalíticos como a "affective or social force, the glue, even when its manifestation is hostility or hatred or something less emotively charged, that shapes an important relationship" (SEDGWICK, 1985, p. 2). Sua ideia central reside na premissa de que o patriarcado costuma obrigar seus sujeitos a expressar somente desejo heterossexual, a repudiar a carga erótica das ligações entre homens e a projetar esses desejos em figuras homossexuais estigmatizadas (WARNER, 1993, p. xiv). Com efeito, constroem-se muitas estruturas homossociais sobre poderosos laços entre homens, mas não se consegue expressar o desejo constituinte em termos eróticos. Sedgwick desenvolve seu argumento utilizando o trabalho do crítico René Girard. Girard defende que a literatura europeia canônica frequentemente iguala os laços poderosos de rivalidade entre homens aos poderosos laços amorosos que ligam homens a mulheres - sem dúvida, ele considera que a importância da rivalidade masculina pode eclipsar a relação amorosa. Quando homens competem por um objeto amoroso feminino, "desire is effected according to the desire of another, that is, if I as a man desire a woman, it is because another man already desires her" (SCHEHR, 1997, p. 178). Para o argumento de Girard, e também para o de Sedgwick, é crucial o fato de que essa intensa rivalidade seja, na verdade, um efeito da formação, do desenvolvimento e da regulação 
da psique da criança. Para chegar a uma identidade sexual fixa, a criança em desenvolvimento deve proceder por meio de "a complicated play of desire for an identification with the parent of each gender: 'the child routes its desire/identification through the mother to arrive at a role like the father's, or vice versa" (SEDGWICK, 1985, p. 22-23). Explicando isso de outra forma, a perversidade polimorfa da criança pré-edipiana (possivelmente um protótipo para queerness) transforma-se em identidade fixa e desejo estável por meio de um processo no qual o desejo pelo outro pai é reprimido. O desejo reprimido resultante, de acordo com Sedgwick, encontra expressão indireta no triângulo amoroso masculino-masculino-feminino quando os homens expressam desejo um pelo outro por meio da mulher pela qual competem. Resumindo, a rivalidade permite aos homens obedecer às leis da heterossexualidade compulsória e, ainda assim, articular intensas paixões homoeróticas inconscientes.

Assim como acontece com a teoria queer em geral, o triângulo de Sedgwick parece se adaptar ao contexto brasileiro apenas parcialmente, dadas as especificidades da identidade sexual no país. É notório que a homossexualidade no Brasil costuma se manifestar conforme dois paradigmas: o modelo "tradicional" e o de "escolha do objeto". ${ }^{1}$ É certo que Sedgwick trabalha dento de uma moldura cultural ocidental e comenta sobre desejo sexual orientado pelo objeto usando exemplos da literatura inglesa do século XIX. Os cafajestes discute claramente atitudes patriarcais relacionadas a sexo e desejo. Sendo esta uma forma de exibir a repressão do desejo homossexual pelo patriarcado, justificaria uma análise sedgwickiana. De fato, o patriarcado estrutura os modelos de identidade sexual que circulavam na sociedade brasileira à época da realização do filme tão claramente quanto no contexto da análise de Sedgwick. Se a teoria dela se presta tão prontamente ao modelo de escolha do objeto, mas faz pouco sentido quando confrontado com o modelo "tradicional", é necessário também ressaltar que nenhum desses modelos pode ser completamente separado do outro, como Ri-

\footnotetext{
${ }^{1}$ A tendência entre os antropólogos tem sido a de contrastar dois modelos aqui. O primeiro determina a identidade pelo papel sexual, e é conhecido como "modelo tradicional" - os homens são ativos/penetradores e, portanto, essencialmente masculinos, ou passivos/penetrados e, portanto, feminilizados. O segundo modelo é o mais claramente influenciado por discursos ocidentais (o médico e o psicológico, por exemplo) e confere identidade com base no objeto de desejo - os homens são heterossexuais se desejam mulheres e homossexuais se desejam homens. Ver Green (2001) e Trevisan (2000).
} 
chard Parker observou (PARKER, 1999, p. 50). Finalmente, a própria Sedgwick rejeita a ideia dos triângulos de rivais como uma forma a-histórica ou platônica. Em vez disso, define esse triângulo como "a sensitive register precisely for delineating relationships of power and meaning, and for making graphically intelligible the play of desire and identification by which individuals negotiate with their societies for empowerment" (SEDGWICK, 1985, p. 27). No mínimo, a crítica de Sedgwick expõe suposições e preconceitos patriarcais e heterossexistas que permanecem incontestados dentro do Cinema Novo. No entanto, quando adaptamos essa crítica para a denúncia explícita do capitalismo no filme, ela proporciona perspectivas úteis sobre como os desejos (sexuais) e os desejos de riqueza, capital e posição social são estruturados da mesma forma, paralelamente e até de maneira inseparável. Assim, o objetivo deste artigo é tanto testar a utilidade da teoria de Sedgwick quanto mostrar as formas como o filme corrobora essa teoria.

\section{Estruturas homossociais}

O filme de Guerra gira em torno de Jandir e Vavá, dois amigos que basicamente se juntam para obter ganho financeiro explorando mulheres. A crise no filme se precipita com a iminente falência do pai de Vavá, que ameaça acabar com o estilo de vida opulento do filho. Para evitar isto, Vavá se alia a Jandir com o intuito de chantagear seu tio rico. Assim, eles planejam seduzir Leda, a namorada do tio, para obter dela fotos comprometedoras. Embora eles consigam as fotos - e traumatizem Leda -, descobre-se que ela não estava mais namorando o tio de Vavá afinal. Leda sugere que a dupla tente o mesmo golpe com Wilma, que é a filha do tio rico (e, portanto, prima de Vavá) mas também objeto do desejo de Vavá. O trio leva Wilma a uma praia, mas os eventos não ocorrem como planejado. Jandir e Vavá acabam brigando. Ao que parece, isto fazia parte dos planos de Leda, ciente de que os sentimentos de Vavá por Wilma entrariam em conflito com sua lealdade a Jandir. No fim do filme, Wilma e Vavá se unem como um casal, enquanto Leda e Jandir partem juntos, porém bastante isolados um do outro.

Indagações gerais sobre motivação e desejo são fundamentais para a história; de fato, o âmago do drama encontra-se na maneira como os dois golpistas, 
tão confiantes de sua dominância sobre as mulheres, tornam-se vítimas de um golpe eles mesmos. Enquanto a motivação de Vavá é principalmente conseguir dinheiro para seu pai, o filme explica o comportamento de Jandir por meio de senso comum: ele quer o carro de Vavá, mas é impelido muito mais pela vontade de entrar no mundo da classe média. Ele age para melhorar de vida e Vavá aparece como o meio para atingir este fim. A fim de demonstrar de forma convincente o desejo homossocial que percorre Os cafajestes, analisarei agora quatro estruturas de significado no filme.

\section{a. $\mathbf{O}$ carro}

O carro usado para levar Leda à praia emerge como figura-chave no tratamento do desejo em Os cafajestes. Ele aparece pela primeira vez quando Jandir e Vavá se preparam para seduzir Leda. Vavá tem que se esconder no porta-malas do carro enquanto Jandir conduz Leda à praia deserta; quando ela ficar nua, Vavá irá saltar do porta-malas e tirar várias fotos comprometedoras dela. Desta maneira, o carro torna-se o mecanismo central por meio do qual o filme comunica o desejo homossocial, conforme discutido por Sedgwick, pois permite a Jandir expressar seu desejo por Vavá através de um substituto. Jandir começa a acariciar o capô do momento em que Vavá se esconde no porta-malas, curvando-se para falar com Vavá e mantendo contato físico com o carro apesar de os transeuntes questionarem esse comportamento aparentemente inexplicável. Um segundo exemplo ocorre mais tarde, quando Jandir, Leda e um Vavá ainda escondido chegam à praia. Jandir sussurra para Vavá enquanto Leda se afasta. Quando ela retorna, Jandir faz novo contato físico ambíguo com o carro, acariciando-o num gesto que se pode considerar erótico. Para observadores externos, o carro aparenta ser o "objeto" da afeição de Jandir. Uma explicação não-sexual inteiramente plausível é que ele apenas gosta muito de carros. Um automóvel caro funciona como símbolo de posição social tanto quanto representa um veículo e foi usado com frequência para representar masculinidade nos filmes noir ocidentais (OSTEEN, 2008, p. 189). É possível, portanto, ler estas cenas como indicadores do desejo de ascensão social de Jandir.

Vale dizer que as atuações em Os cafajestes são primariamente naturalistas à medida que os atores se esforçam em representar seus personagens e os even- 
tos de maneira realista. James Naremore descreve a performance naturalista como derivada da obra de Konstantin Stanislavski e que tem como objetivo criar uma ilusão de verossimilhança, comunicar uma verdade emocional e evitar artifícios explícitos ou teatralidade (NAREMORE, 1988, p. 2-3). Naremore observa que atores geralmente utilizam objetos de cena para ajudá-los na maneira de expressar significado: "part of the actor's job [...] is to keep objects under expressive control, letting them become signifiers of feeling" (NAREMORE, 1988, p. 87). Caso assim seja, Jece Valadão (que interpreta Jandir) pode ter usado as carícias para simbolizar a paixão de seu personagem por carros, proporcionando a ele uma persona masculina ligada à propriedade de um veículo e à ostentação.

O carro, porém, pertence a Vavá e será dado a Jandir como pagamento por sua participação no golpe. Sim, Jandir cobiça o carro, mas ele também o cobiça por pertencer a Vavá. Ao mesmo tempo, o espectador foi informado da presença de Vavá dentro do carro apenas segundos antes, graças a uma tomada do ponto de vista do personagem. Quando Jandir fala ao carro, sabemos que está secretamente conversando com Vavá. Portanto, o roteiro e a cinematografia sugerem que há algo mais que capital em jogo nesta trapaça, uma vez que qualquer manifestação de intimidade física de Jandir com o carro também se dirige a Vavá. Adaptando-se a análise de Sedgwick aqui, pode-se argumentar que Jandir descobre ser possível expressar, nestes exemplos de desejo, competição e consumo postergado, precisamente algo que, de outra forma, seria reprimido: um desejo por Vavá. O capô e, na verdade, todo a estrutura do carro em geral servem como uma superfície, uma pele metálica, que evita e permite contato íntimo ao mesmo tempo. Em outras palavras, a expressão do desejo por contato e intimidade entre os homens dá-se de maneira mais explícita quando se torna fisicamente impossível.

\section{b. A abertura}

Enquanto se dirige à praia com Leda, Jandir passa informações sobre o tempo para Vavá a fim de que este ajuste a abertura de sua câmera de acordo com a intensidade da luz. Jandir grita: "Atenção! Sol bonito! Diafragma onze!” Quando Leda indaga sobre o estranho comentário, ele responde que "cada sol tem um nome diferente" e justifica-se dizendo que estava com vontade de gritar. Assim, 
ele disfarça informações destinadas a Vavá como mera expressão divertida e caprichosa de frustração. $\mathrm{O}$ espectador, porém, sabe que ele está flertando com Leda para conversar secretamente com Vavá. Esta sequência é cheia de ironia: Jandir está seduzindo Leda com uma mensagem cifrada contendo informação que será brevemente usada contra ela, que é encorajada a também gritar "Diafragma onze!", levando adiante sua própria exploração. O truque de Jandir neste caso, todo o esforço de sedução - encontra-se na mesma capacidade do carro anteriormente, ou seja, como um condutor ou substituto. Um encontro heterossexual está facilitando um envolvimento com uma pessoa do mesmo sexo.

\section{c. A orquídea}

A terceira estrutura de significado emerge após a humilhação de Leda, quando ela promove uma trégua desconfortável com Jandir e Vavá. Enquanto eles retornam para a cidade, os dois homens conversam entre si; Leda permanece em silêncio. Vavá se gaba de seus êxitos anteriores com as mulheres ao presenteá-las com uma orquídea que floresce no dia do aniversário delas. Jandir comenta que esse tipo de comportamento é cheio de "frescura". A palavra "frescura" origina-se de "fresco, with the dual meaning of a fairy or faggot and something fresh", e é usada aqui claramente com esta definição pejorativa (GREEN, 2001, p. 27). Vavá defende-se; Jandir estaciona o carro, arromba uma floricultura e rouba uma caixa de orquídeas para provar seu argumento. Orquídeas são ricas em significado. Escrevendo sobre filmes noir, Richard Dyer sugere que a orquídea conota homossexualidade: "orchids are rare and precious, signs of extravagant love during heterosexual courtship, they are also suspect, over-elaborate blooms [...] the product of unnatural cultivation" (DYER, 2004, p. 91-92). As qualidades da orquídea combinam com a tendência a representar os homossexuais como decadentes no filme noir - homens bem-vestidos que possuem um gosto esotérico por decoração excessiva (DYER, 2004, p. 91). Tal simbologia sugere que o gesto de Vavá tem conexões semânticas tanto com a homossexualidade quanto com a riqueza. É certo que as condições ambientais próprias ao seu cultivo são mais abundantes no Brasil, mas a orquídea pode ainda conotar mais que desejo 
heterossexual em Os cafajestes devido à sua aparência elaborada. ${ }^{2}$ Karl Posso chama atenção para um outro duplo sentido semântico: como flores, orquídeas são literalmente os órgãos reprodutores da planta, além de comportarem associação etimológica com a genitália, pois a palavra "orquídea" deriva da palavra do grego antigo para testículo, orkhis (POSSO, 2003, p. 77). A orquídea está repleta de significados que complicam sua função declarada de validar a masculinidade de Vavá. Em vez de confirmar a heterossexualidade dele, a orquídea contamina-a com ambivalência. Isto fica evidente quando Jandir resolve testar a teoria de Vavá na estrada. Ele acelera o carro até alcançar um outro automóvel dirigido por uma loira. Vavá estica o corpo para fora da janela e oferece orquídeas à mulher gritando "Olha aí gostosa!" e atirando as flores no carro dela. Como ocorre com os exemplos anteriores, esta sequência possui uma explicação aparentemente inocente: a identidade masculina é contestada e confirmada por meio do diálogo, o que empresta à cena um ar de rivalidade amistosa. No entanto, embora a amostra de ousadia masculina de Vavá pareça inteiramente heterossexual em seu conteúdo, ela também não poderia nunca ser confundida com um gesto romântico sério. Trata-se de uma performance de romance, uma brincadeira entre Jandir e Vavá. E ela sugere mais do que Vavá pretendia, revelando um pouco das intenções mais profundas a motivar o ato.

\section{d. As consequências}

Cada uma das estruturas de significado e desejo que se delineiam acima indica desejo homossocial em uma forma comparável por meio de sugestão. Mais ainda, articula-se o desejo homossocial por meio de commodities (o carro, a câmera, e a orquídea), o que modula o comportamento dos rapazes com desejos de riqueza e posição social. Agora, chamo a atenção para um último exemplo de desejo homossocial que demonstra sua importância para a identidade masculina de maneira mais literal. Conforme observei acima, a situação se inverte

\footnotetext{
${ }^{2}$ Abraham e Vatsala comentam que, embora os campos do Brasil sejam demais secos para o cultivo de orquídeas, e a região amazônica seja pobre em plantas da espécie, as regiões tropicais do sudeste do país encontram-se entre as três de maior cultivo de orquídeas no mundo (as outras duas são regiões tropicais da África e as regiões indo-burmesa e do sudeste asiático). Ver (ABRAHAM; VATSALA, 1981, p. 12).
} 
para os dois "cafajestes" a partir da metade do filme, quando Leda manipula para Wilma tomar o seu lugar na formação triangular, fazendo com que os dois homens cheguem às vias de fato. A sequência continua noite adentro. Quando Vavá e Wilma discutem sua relação em particular, Jandir tenta fazer sexo com Leda, mas não consegue. Dada a frequência com que Jandir e Vavá são mostrados tentando seduzir e dominar mulheres, pode-se dizer que eles aderem a uma versão de masculinidade que preza a habilidade sexual e o controle sobre as muIheres. Sendo assim, nada poderia colocar essa masculinidade mais em dúvida do que uma falha erétil (WEBB, 1998). Resta a Jandir uma opção para redimir sua virilidade: ele acaba forçando Wilma a ter relações sexuais com ele. Esse ato se desenrola às vistas de Vavá e Leda, repetindo a estrutura de desejo homossocial uma última vez. Jandir, ao que parece, somente consegue fazer sexo quando olha para Vavá. Em outras palavras, o sexo com mulheres aparentemente só é possível para Jandir com referência a (e, aqui, literalmente na presença de) outro homem. A mesma ação que redimiria sua habilidade heterossexual acaba por colocá-la sob suspeita. Em verdade, sugiro que isso apresenta a masculinidade de Jandir como algo contraditório e instável, pois seus atributos constitutivos - uma amostra exibicionista de desejo heterossexual e habilidade sexual - dependem fundamentalmente do desejo entre homens e por ele são moldados.

\section{Ideologia e desejo homossocial}

Até agora, estabeleci como o filme destaca a fragilidade da identidade masculina em relação ao desejo homossocial. Mas o que isto significa para a sua mensagem política maior? Para responder a esta pergunta, devemos observar dois outros exemplos de desejo homossocial e atentar para como o conteúdo diegético interage com a estética do filme. Enquanto Leda tenta organizar a chegada de Wilma, Jandir e Vavá esperam num forte costeiro. Duas mulheres se aproximam e uma delas pede fogo a Jandir. Novamente, o filme faz alusão a uma formulação triangular: a encenação sugere que os dois homens estão competindo entre si. Logo após a chegada das jovens, o filme se bifurca em duas conversações, que se desenvolvem em paralelo: em ambas, Jandir e Vavá fazem às mulheres uma série de perguntas cada vez mais pessoais. É uma sequência incomum, no mínimo, porque Jandir e Vavá aparentemente adotam uma atitu- 
de quase mecânica e indiferente em relação às mulheres apesar de os diálogos estarem repletos de clichês de sedução heterossexual. Jandir se oferece para resgatar a primeira mulher da rotina mundana de escola e família, e oferece-lhe "empregadas, boas roupas" caso ela aceite segui-lo. Vavá pergunta à segunda sobre seu pai. Esta conversa é logo intercalada com um diálogo entre Jandir e a primeira mulher sobre moralidade e a igreja.

Randall Johnson explica que essa montagem irregular e desajeitada produz um Verfremsdungseffekte, expressão referente a um dos conceitos centrais na abordagem teórica da dramaturgia por Bertolt Brecht (JOHNSON, 1984, p. 97). Trata-se de algo que merece uma breve descrição antes de prosseguirmos.

Verfremdung é um dos conceitos fundamentais para a teoria de Brecht. Relaciona-se com o Entfremdung (alienação) de Marx e pode ser traduzido como "desalienação", "desilusão", "deslocamento" e "desfamiliarização". Quando aplicada ao cinema, essa técnica tem por fim ejetar o espectador da absorção narrativa por meio de um momento de autorreferência cinemática: ao chamar atenção para a sua artificialidade, o filme indica que, em vez de um produto mágico e a-histórico, emerge de um contexto social e histórico determinado por relações materiais (o capital). Se o filme se localiza em um contexto histórico, isto também pode ser dito sobre os sistemas ideológicos em funcionamento dentro dele. Fredric Jameson explica que eles são históricos, e a isso pode-se acrescentar, como corolário político, que são feitos ou construídos por seres humanos; portanto, seres humanos podem também modificá-los ou substituí-los completamente (JAMESON, 1998, p. 40). Guerra utiliza Verfremsdungseffekte, ou "efeitos V" com parcimônia em Os cafajestes, mas os momentos mais provocantes do filme são provavelmente os mais brechtianos, como Johnson indica (JOHNSON, 1984, p. 97). Neste segmento, Johnson sugere, a montagem irregular e desajeitada produz um efeito-V ao desorientar o espectador e dissuadi-lo de uma apreciação desatenta da narrativa (JOHNSON, 1984, p. 97). A sequência também se mostra reflexiva: ao combinar mal, por assim dizer, áudio e imagem, o interlocutor e a resposta, o filme quebra o ilusionismo narrativo e se revela como um construto. Os espectadores deixam o modo de experiência passiva e são instruídos a ver o conteúdo com distanciamento crítico. O "conteúdo" em questão são os vários fragmentos das respostas das mulheres às perguntas de Jandir e Vavá, que formam parte dos sistemas de crenças usados para controlar a sexualidade feminina. A cinematografia tremida aqui traça uma correlação en- 
tre os recortes de fragmentos ideológicos e a produção da montagem cinematográfica. Ao fazer essa correspondência enquanto chama atenção para o seu próprio processo de produção, o filme ilumina a característica artificial das próprias ideologias, enfatizando sua determinação pelo contexto histórico. Em resumo, o que aparenta ser um simples flerte dos dois "cafajestes", em realidade, constitui-se numa cena durante a qual o patriarcado, o catolicismo, e as narrativas sobre a sexualidade feminina ficam expostos como fragmentos artificiais, que a ordem social normalmente entrelaça para controlar os cidadãos. Após ambos fracassarem na tentativa de conquistar as mulheres, o próprio Jandir nota que Vavá quase "ganhou uma orquídea viva". Este retorno à imagem da orquídea, especialmente no contexto de uma tentativa de sedução mal-sucedida, também nos conduz de volta à ligação homossocial e, principalmente, a um símbolo que infunde ambivalência na heterossexualidade de Vavá.

Gostaria de chamar a atenção para o que é provavelmente o mais célebre exemplo de efeito-V em Os cafajestes, a assim chamada "tomada longa", e demonstrar, uma vez mais, que o desejo homossocial tem um papel fundamental na crítica que Guerra dirige à ordem social vigente. A tomada longa começa quando Jandir vai embora de carro com as roupas de Leda, deixando-a nua na praia. Jandir retorna e faz o carro circundar Leda enquanto Vavá a fotografa, gritando e provocando. O carro vai se aproximando cada vez mais dela durante esta sequência de cerca de quatro minutos, e o congelamento de imagem transforma o filme numa fotografia de Leda implorando clemência. Os críticos exploraram a forma como a câmera é representada como uma arma nesta sequência e analisaram como a mise-en-scène e o trabalho de câmera proporcionam ao espectador uma subjetividade dominadora (DA SILVA, 2014, p. 139; DE PINTO, 2015 , p. 155). Jean-Claude Bernardet argumenta que a desumanização de Leda visava atiçar a indignação pública e contradiz as pretensões de notoriedade do filme ao mesmo tempo em que demonstra "mais autodesprezo do que vontade de atuar sobre o mundo" (BERNARDET, 1977, p. 108). Johnson é mais simpático ao filme ao sugerir que a tomada longa revela a reificação - a noção de que se pode remover um objeto de seu contexto material e torná-lo um fetiche na forma de uma coisa mágica e desejável - a fim de trazer este processo para dentro da crítica. Eu acrescentaria que as fotos de Vavá também são commodities que se pode trocar por lucro. 
O valor das fotos (e a razão pela qual os dois rapazes as usam para chantagem) baseia-se primariamente no fato de que elas comprometem a posição social de Leda e, assim, mancham indiretamente a reputação do tio de Vavá, que está ligado a ela. Neste sentido, a tomada longa lida com a conhecida equivalência entre mulheres e objetos e entre homens e sujeitos. Cada sistema ideológico invocado aqui (capitalismo, patriarcado) se baseia na oclusão das condições históricas e materiais: os objetos perdem seu contexto material e são recondicionados como commodities da mesma forma que as mulheres são naturalizadas como objetos. Aqui, no entanto, Guerra nos apresenta um efeito-V, produzido em primeira instância pela identificação que o filme faz entre a câmera de filmagem e a máquina fotográfica de Vavá. De maneira reflexiva, esta equação revela o filme como um objeto estético ao apontar para seus próprios processos de produção. Assim como o filme está, de fato, localizado em um contexto histórico, também o estão os sistemas ideológicos citados - fabricados ou construídos, ou "históricos" nas palavras de Jameson - e, portanto, abertos ao debate (JAMESON, 1998, p. 40).

A saída de Vavá do porta-malas assinala o fim de qualquer pretensão de sedução. Agora, Leda está ciente do que está acontecendo - e o público assiste ao relacionamento triangular como uma imagem potente do abuso e degradação a que ela é submetida. Aqui, pode-se dizer que duas explicações para o comportamento de Jandir e Vavá parecem existir em paralelo. Por um lado, o filme claramente mostra o estímulo financeiro como motivo para tratar Leda daquela maneira: Vavá deseja tirar o maior número de fotos escandalosas possível; suas provocações e seus gritos procuram intensificar o terror e a humilhação de Leda. No entanto, como já argumentei, o filme também complicou as explicações para o comportamento dos rapazes ao chamar atenção repetidas vezes para o papel implícito do desejo homossocial. Em vez de incluir uma interpretação na outra, pode-se argumentar que a tomada longa mostra como as motivações dos rapazes (por dinheiro e de um rapaz pelo outro) estão conectadas, até mesmo emaranhadas e difíceis de ser separadas.

É nesse ponto que fica aparente uma diferença entre o modelo de Sedgwick e o relato do filme. Em primeiro lugar, Leda não é, em Os cafajestes, um objeto desejável na medida em que os homens não estão competindo abertamente por seu amor. Em vez disso, sua interação com ela visa enganar o tio para que ele repasse mais dinheiro a Vavá. Ao colocar o desejo homossocial na função de fator de motivação principal, a análise de Sedgwick pode não ser capaz de explicar to- 
talmente a misoginia explícita e o tratamento cruel de Leda nesta espécie de triângulo erótico, que é, segundo muitos críticos, bárbaro e desumano. O esquema de Sedgwick, porém, é útil ao mostrar que o desejo homossocial restringido por uma estrutura social capitalista frequentemente acaba com as mulheres pagando o preço por essa repressão quando são usadas como condutores para aquele desejo. Em segundo lugar, a análise sedgwickiana não pode ser feita ao custo da compreensão das dimensões de classe nesta cena, discutidas em detalhes por Johnson. Contudo, é possível que múltiplas explicações para a motivação (múltiplas interpretações do desejo) sejam todas válidas, emaranhadas e coexistentes durante a longa tomada. Em outras palavras, Os cafajestes, analisado por meio da teoria de Sedgwick, indica como a homossocialidade masculina está interligada com a cultura de consumo capitalista. Esta leitura também permite-nos ver os efeitos deletérios que tal ligação produz nas mulheres presas a esse sistema. Mas essa análise também permite vislumbrar como a verdade sobre o desejo de um indivíduo pode ser difícil de apreender nos termos diretos do modelo orientado pelo objeto.

\section{Conclusões}

Para concluir, gostaria de enfatizar a importância de uma leitura queer deste filme. Johnson descreve a estrutura de Os cafajestes como sendo uma série de trocas que "in the end lead to nothing at all" exceto à reificação dos seres humanos ao mesmo tempo em que o dinheiro basicamente determina as relações interpessoais no filme (JOHNSON, 1984, p. 96). Uma leitura queer, diferente, permitiu mostrar que isso não é tudo. De fato, as relações em Os cafajestes são regidas pelo dinheiro, mas elas também são determinadas por ideologias que moldam o comportamento sexual e de gênero. Ao examinar essas relações por meio de uma perspectiva queer, podemos ver até que ponto o filme vai para expor a artificialidade daquelas ideologias. Pode-se também observar como o filme explica as formas pelas quais o patriarcado se entrelaça com o capitalismo, uma percepção que sinaliza novas possibilidades de transformação social.

Gostaria de fazer uma ressalva no uso de teoria queer para a interpretação deste filme. A análise de Sedgwick prioriza o homossocial como, de alguma forma, base para outras relações entre homens. No entanto, Os cafajestes mostra- 
-nos como os desejos por dinheiro, riqueza e posição social são, muitas vezes, indistintos do desejo homossocial. Em outras palavras, seria um erro simplesmente ignorar o fato de que, como em outros filmes da mesma época, uma leitura marxista está prontamente disponível em Os cafajestes: classe social, propriedade e consumo figuram largamente nas relações masculinas do filme. A leitura do desejo homossocial de Sedgwick, nesse contexto, deve tornar o quadro ainda mais complexo em vez de restringir o que vimos. As motivações financeiras que movem os atos traiçoeiros de Jandir e Vavá se tornam turvas, pois estão ligadas aos desejos ocultos de um rapaz pelo outro.

Leituras queer do filme, e dos filmes políticos da mesma época em geral, não devem, portanto, simplesmente substituir um elemento de motivação por outro; leituras de política sexual não devem apagar as de política de classe. Em vez disso, devemos explorar as maneiras como elas se entrelaçam e se tornam difíceis de separar. A teoria de Sedgwick auxilia nesse trabalho, mas também se arrisca a priorizar o desejo homossocial em relação a outros repertórios analíticos. Aplicar uma visão queer a filmes no contexto brasileiro, especialmente àqueles do período analisado aqui, significa ajustar teorias tanto ao tema quanto à situação cultural e ao ambiente histórico. Mesmo assim, uma vez analisados sob a perspectiva queer, filmes como os de Guerra podem revelar a intensidade com que múltiplos sistemas de opressão (de classe, gênero ou sexualidade) estão interligados e se mostram históricos, o que abre oportunidades para uma transformação mais eficaz desses sistemas. 


\section{Referências}

ABRAHAM, A.; VATSALA, P. Introduction to orchids, with illustrations and descriptions of 150 south indian orchids. Trivandrum: Tropical Botanic Garden and Research Institute, 1981.

BERNARDET, Jean Claude. Brasil em tempo de cinema: ensaios sobre o cinema brasileiro. São Paulo: Paz e Terra, 1977.

CHAVES, R.; CABAÇO, J. L. Entrevista: Ruy Guerra cidadão de várias pátrias, passageiro de diferentes revoluções. Via Atlântica, São Paulo, n. 21, p. 133-143, 2012.

DA SILVA, A. L. Revisitando Ruy Guerra: Um percurso metodológico pela análise fílmica de Os cafajestes(1962). Toma Uno, n. 3, p. 135-144, 2014.

DA SILVA, A. L.; RIBEIRO, R. R. O Cinema brasileiro e as identidades híbridas em Ruy Guerra: O olhar latino-africano de um cidadão da vida Brasiliana. Journal for Brazilian Studies, n. 1, p. 441-471, 2014.

DE AZEVEDO, A. P. F.; CUNHA, E. L. Disrupção imagética: desocidentalizar os corpos, desconstruir a heteronormatividad'. Via Atlântica, n. 24, p. 13-28, 2013.

DE PINTO, C. E. P. 11 Câmera-arma: a representação das funções sociais da fotografia em Os cafajestes (Ruy Guerra, 1962). Revista Brasileira de História da Mídia, v. 2, n. 2, 2015.

DYER, R. Queer noir. In BEHSHOFF, H.; GRIFFIN, S. (Eds.). Queer cinema: the film reader. London: Routledge, 2004, p. 89-104.

GREEN, J. N. Beyond Carnival: male homosexuality in twentieth-century Brazil. Chicago: University of Chicago Press, 2001.

HODGSON, J. Queer Possibilities in Glauber Rocha's Barravento. Studies in Spanish and Latin American Cinema. Forthcoming, 2017.

HODGSON, J. N. Male homosexuality in brazilian cinema of the 1960s and 1970s. Tese (Doutorado) - University of Manchester. Manchester. 2013, pp. 1-274.

JAMESON, F. Brecht and method. London: Verso, 1998.

JOHNSON, R. Cinema novo x 5: masters of contemporary brazilian film. Austin: University of Texas Press, 1984.

JOHNSON, R.; STAM, R. Brazilian cinema. New York: Columbia University Press, 1995.

MORENO, A. A personagem homossexual no cinema brasileiro. Rio De Janeiro: Funarte, 2001.

NAREMORE, J. Acting in the cinema. California: Univ of California Press, 1988.

NETO, J. N. Anthropophagic queer: A Study on Abjected Bodies and Brazilian Queer Theory in Literature and Film. Tese (Doutorado) - City University of New York. New York, 2015. 
OSTEEN, M. Noir's Cars: Automobility and amoral space in American film noir. Journal of Popular Film \& Television, v. 35, n. 4, p. 183-192, 2008.

PARKER, R. G. Beneath the Equator: cultures of desire, male homosexaulity and emerging gay communities in Brazil. New York: Routledge, 1999.

POSSO, K. Artful Seduction: homosexuality and the problematics of exile. Oxford: Legenda, 2003.

SCHEHR, L. R. Parts of an andrology: on representations of men's bodies. Stanford: Stanford University Press, 1997.

SEDGWICK, E. K. Between men: English literature and male homossocial desire. New York: Columbia University Press, 1985.

SINFIELD, A. Cultural politics, queer reading. London: Routledge, 2005.

SUBERO, G. Gender and sexuality in Latin American horror cinema. London: Palgrave Macmillan, 2016.

TREVISAN, J. S. Perverts in paradise. Trans. Martin Foreman. London: GMP, 1986.

TREVISAN, J. S. Devassos no paraíso: a homossexualidade no Brasil, da colônia à atualidade. Rio de Janeiro: Record, 2000.

WARNER, M. Fear of a queer planet: queer politics and social theory. Minneapolis: University of Minnesota Press, 1993.

WEBB, S. Masculinities at the Margins: representations of the malandro and the Pachuco. In BUENO, E. P.; CAESAR, T. (Eds.). Imagination beyond nation: latin american popular culture, 1998, p. 227-64. 